\title{
Contactless DC Connector Concept for High-Power-Density 380-V DC Distribution System
}

\author{
Yusuke Hayashi ${ }^{* a)}$ Member, Hajime Toyoda* Member \\ Toshifumi Ise ${ }^{*}$ Fellow
}

(Manuscript received Jan. 20, 2014, revised June 25, 2014)

\begin{abstract}
A contactless DC connector concept has been proposed for next-generation 380-V DC distribution systems in data centers. An LLC resonant DC-DC converter topology with gallium nitride ( $\mathrm{GaN})$ power transistors has been applied to realize a highly efficient inductively coupled contactless connector. A prototype of a $1.2-\mathrm{kW} 384 \mathrm{~V}-192 \mathrm{~V}$ contactless connector has been fabricated. An efficiency of over $95 \%$ and an ideal power density of over $5.0 \mathrm{~W} / \mathrm{cm}^{3}$ have been confirmed experimentally under 500-kHz operation. Design considerations for the proposed connector have been also conducted, and the approach for achieving a higher power density of $10 \mathrm{~W} / \mathrm{cm}^{3}$ has been presented. The proposed concept contributes to realizing a high-power-density DC distribution system because the functions for both the isolated DC-DC converter and conventional connector are integrated in a single instrument.
\end{abstract}

Keywords: Contactless power supply, DC Distribution, isolated DC-DC converter, Gallium Nitride

\section{Introduction}

The amount of network traffic in the data centers has recently been rapidly increasing due to the widespread use of information and communication technology (ICT) equipment ${ }^{(1)}$. Energy saving in the data centers will contribute to solving some of our global environmental problems. Since 2008, the NTT (Nippon Telegraph and Telephone) Group has been developing 380-V DC distribution system that goes beyond the conventional $48 \mathrm{~V} \mathrm{DC}$ distribution system to realize highly efficient and space-saving (high-power-density) power supply ${ }^{(2)(3)}$.

Intensive studies have been carried out for high-powerdensity power electronics converter, and the output power density of the converter for 380-V DC distribution system is now at a level of $1 \mathrm{~W} / \mathrm{cm}^{3}$. In the field of $R \& D$, power converters with more than $10 \mathrm{~W} / \mathrm{cm}^{3}$ have been reported ${ }^{(4)-(6)}$. As the power density of the power converter increases, the volume of peripherals such as connectors will not be negligible. The power density of the connector for several $\mathrm{kW}$ output power in 380-V DC distribution system is now at a level of $10 \mathrm{~W} / \mathrm{cm}^{3}$. To realize higher power density $380-\mathrm{V}$ DC distribution system, comprehensive design is indispensable taking the influence of peripherals into consideration.

The DC connector based on the inductively coupled contactless power transfer technology is one of solutions for future high power density DC distribution system. A socket and a plug of the DC connector can be developed by using the primary and the secondary circuits of the isolated DC-

a) Correspondence to: Yusuke Hayashi. E-mail: y_hayashi@eei. eng.osaka-u.ac.jp

* Division of Electrical, Electronic and Information Engineering, Graduate School of Engineering, Osaka University

2-1, Yamada-Oka, Suita, Osaka 565-0871, Japan
DC converter respectively. This means that the high power density DC-DC converter which constitutes the 380-V DC distribution system can be integrated into the conventional DC connector to shrink the total component volume.

In the 380-V DC distribution system for data centers, high power density design methodology for the isolated DC-DC converter can be directly applied for the contactless DC connector because the loading apparatus is not mobile and the influence of the positioning gap don't have to be considered. The non-regulated converter topology is also available to achieve higher power density in case that the voltage regulation is achieved by front-end and back-end converters in the 380-V DC distribution system. Although the contactless power supply technology for DC connectors has been reported ${ }^{(7)(8)}$, the concept specialized for data center application has not been reported to realize high power density contactless DC connector.

In this paper, a contactless DC connector concept is proposed to realize high-power-density 380-V DC distribution system in data centers. The DC distribution system using proposed DC connectors is introduced in chapter 2 . Then, details of the circuit configuration and characteristics of the connector with the short-distance and the inductively coupled contactless power transfer are described. The feasibility of the proposed connector is verified experimentally in chapter 3 . In chapter 4 , design consideration for the connector is conducted to achieve the power density of over $10 \mathrm{~W} / \mathrm{cm}^{3}$.

2. Concept for Next-Generation 380-V DC Distribution Sysmte Using Contactless DC Connector

2.1 Concept to Realize Higher Power Density 380-V DC Distribution System Figure 1 shows the power density trend of isolated DC-DC converters for telecom power 
supply. In research and development level, power converters with $10 \mathrm{~W} / \mathrm{cm}^{3}$ has been developed for $380-\mathrm{V}$ DC distribution system ${ }^{(9)}$. The power density of a connector for $380-\mathrm{V}$ DC distribution system is also shown in Fig. 1. Volume of a socket in a connector is $100 \mathrm{~cm}^{3}$, and the power density per socket is $10 \mathrm{~W} / \mathrm{cm}^{3}$ in the case of the output power of $1 \mathrm{~kW}$.

Figure 2 shows the schematic diagram of the conventional 380-V DC distribution system for data centers. In Fig. 2, connectors with metal contacts and isolated DC-DC converters are installed in low voltage (e.g. $380 \mathrm{~V}, 48 \mathrm{~V}$ and $12 \mathrm{~V}$ ) DC distribution line for power supply units (PSU) and onboard power supplies behind the rectifier. The power density of power converters is now at a level of $10 \mathrm{~W} / \mathrm{cm}^{3}$ in $\mathrm{R} \& \mathrm{D}$, and the converters over $50 \mathrm{~W} / \mathrm{cm}^{3}$ is now commercially available for on-board power supply. The influence of peripherals will become obvious in near future.

Figure 3 shows the schematic diagram of the proposed next-generation 380-V DC distribution system with inductively coupled contactless DC connectors. Contactless connectors are only installed in the $380-\mathrm{V}$ DC distribution line

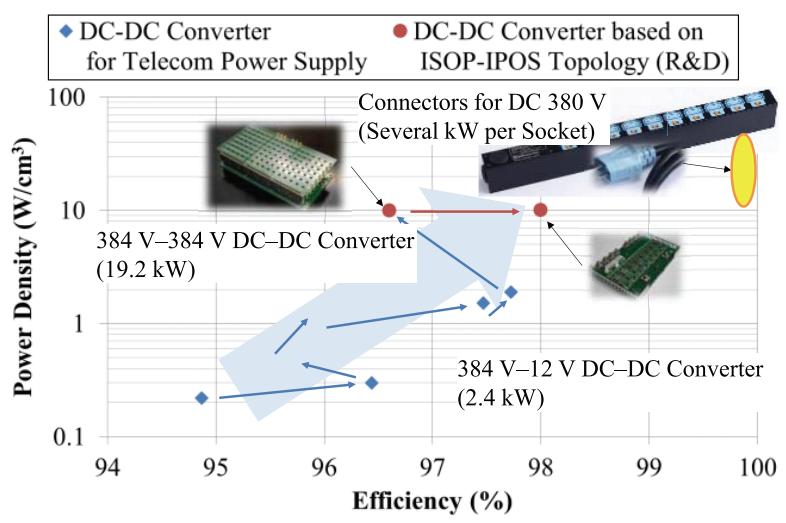

Fig. 1. Power density roadmap for isolated DC-DC converters for telecom power supply and DC connector for 380-V DC distribution system in front of power supply units. A primary and a secondary circuits of an isolated DC-DC converter are utilized as a pair of a socket and a plug respectively. The primary and the secondary circuits are connected via the inductive coupling in a short-distance.

Table 1 shows the power densities of installed components in the current 380-V DC distribution system and the proposed DC distribution system with the contactless DC connector. The transformer for the fundamental frequency of $50 \mathrm{~Hz}$ or $60 \mathrm{~Hz}$ is removed and the contactless DC connector plays a role in both the metal contact connector and the PSU in the proposed DC distribution system. By removing the transformer, the power density in the AC interface can be improved from $0.39 \mathrm{~W} / \mathrm{cm}^{3}(=(0.66 \times 0.95) /(0.66+0.95))$ to $0.95 \mathrm{~W} / \mathrm{cm}^{3}$ which corresponds to the power density of the rectifier. By employing the contactless DC connector, the power density in the DC interface can be improved from $5 \mathrm{~W} / \mathrm{cm}^{3}(=(10.0 \times 10.0) /(10.0+10.0))$ to $10 \mathrm{~W} / \mathrm{cm}^{3}$. Higher power density DC distribution system will be achieved because the number of installed instruments can be reduced in the next-generation DC distribution system.

2.2 Required Performance for Contactless DC Connector Environment of the 380-V DC distribution system in data centers affects the specifications for the contactless DC connector. The 380-V DC distribution system has following characteristics.

Table 1. Power densities of installed components in 380-V DC distribution system

\begin{tabular}{|c|c|c|c|c|}
\hline & \multicolumn{2}{|c|}{$\begin{array}{l}\text { Current } 380-\mathrm{V} \\
\text { DC Distribution }\end{array}$} & \multicolumn{2}{|c|}{$\begin{array}{l}\text { Next-Generation } \\
\text { DC Distribution }\end{array}$} \\
\hline & Component & $\mathrm{W} / \mathrm{cm}^{3}$ & Component & $\mathrm{W} / \mathrm{cm}^{3}$ \\
\hline $\mathrm{AC}$ & Transformer & 0.66 & HV & \multirow{2}{*}{0.95} \\
\hline Interface & Rectifier & 0.95 & Rectifier & \\
\hline $\mathrm{DC}$ & Connector & 10.0 & Contactless & \multirow{2}{*}{10.0} \\
\hline Interface & PSU & 10.0 & DC Connector & \\
\hline
\end{tabular}

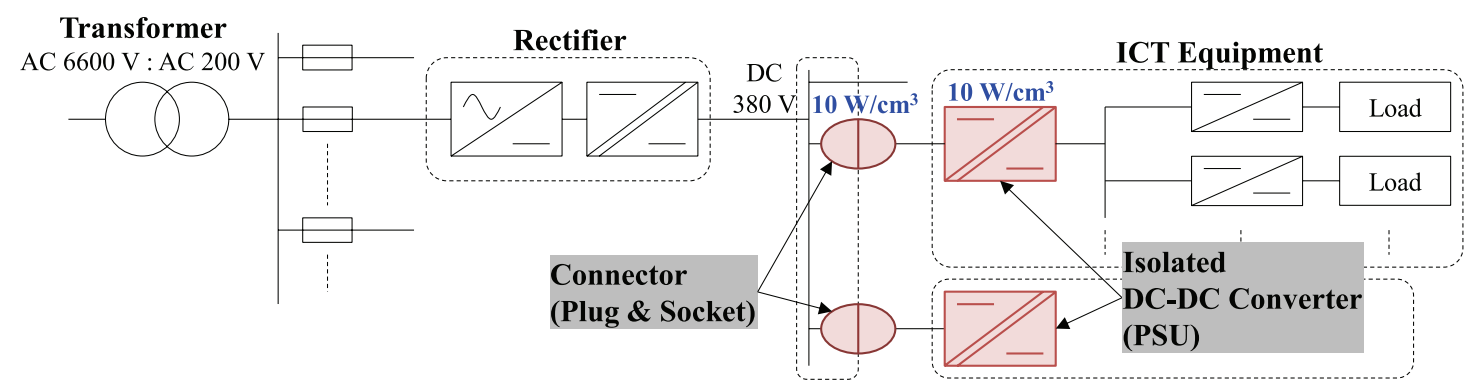

Fig. 2. Configuration of conventional 380-V DC distribution system

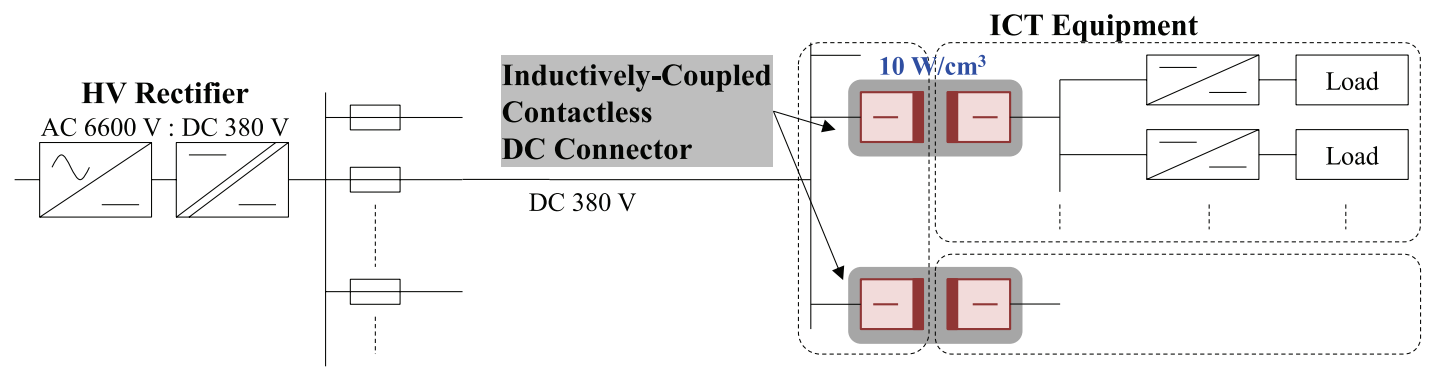

Fig. 3. Configuration of next-generation 380-V DC distribution system using contactless DC connector 
- Installed loading apparatus is known. The ICT equipment as the servers is mainly assumed and its electrical behavior is also well-known.

- The connection and the disconnection of the ICT equipment are infrequent. These actions are mainly conducted in the case of the trouble and the scheduled maintenance.

- The installed loads are utilized in a room. The ambient temperature and the humidity are strictly controlled by the external air-conditioning machines.

Usage environment for the contactless DC connector are summarized as follows taking the aforementioned characteristics into account.

- Electric power through the connector is basically stable and the rapid load variation is infrequent.

- The operating temperature and the humidity are stable. The forced-convection cooling is available for the connector because of the air-conditioning equipment in the room.

- The input voltage of the connector can be controlled by the front end converters as Rectifiers in Figs. 2 and 3. The output voltage can be compensated by the DC-DC converter in ICT equipment. The function of the voltage regulation is not required for the contactless DC connector. The functions of the galvanic isolation and the voltage transformation are essential.

- The output voltage of the connector should be compatible with some voltage levels as $380 \mathrm{~V}, 48 \mathrm{~V}$ and $12 \mathrm{~V}$.

- The position gap between the primary transmitter and the secondary receiver in the connector is controllable because the connected loads are utilized fixedly. This means that the coupling coefficient of the transformer and the circuit parameters for the resonant circuits are also controllable.

The LLC resonant DC-DC converter topology has been applied for the contactless DC connector here. The advantages and disadvantages of its topology are summarized as follows.

- High efficiency can be achieved by ZVS (zero voltage switching) of the main switches and ZCS (zero current switching) of the rectifier diodes. The commercially available isolated DC-DC converter based on the LLC topology has achieved the maximum efficiency of $98 \%$ and the power density of several tens of $\mathrm{W} / \mathrm{cm}^{3}{ }^{(10)}$.

- ISOP (input series and output parallel) and IPOS (input parallel and output series) topologies are available in the LLC converter topology. Arbitrary input and output voltages are selectable by ISOP and IPOS topologies with low voltage LLC converters ${ }^{(11)}$.

- The LLC converter may not achieve ZVS and ZCS in the case of the rapid load variation, because the conditions for the soft switching depend on the load condition significantly. The transient response of the output voltage control may have large delay because the voltage gain also depends on the load condition largely and the frequency modulation control is generally applied in the LLC converter.

The LLC resonant converter has disadvantages for the soft switching operation and the voltage regulation under the rapid load variation. However, these disadvantages do not have to be considered in the contactless DC connector appli- cation in the 380-V DC distribution system. Highly efficient DC connector will be developed by taking full advantages of the LLC resonant converter topology.

\section{Demonstration of Contactless DC Connector Using GaN Power Device}

3.1 Contactless DC Connector Based on LLC Resonant DC-DC Converter Topology The circuit configuration of the LLC converter for the connector is shown in Fig. 4. The availability of LLC converter has been reported and this topology has been applied for the wireless power transfer ${ }^{(12)(13)}$. The zero voltage switching (ZVS) of transistors and the zero current switching (ZCS) of diodes achieve high efficiency. In the case that turn ratio of the transformer $n$ is 1 , the voltage gain $\mathrm{M}$ and the phase angle $\theta$ are calculated by following Eqs. (1), (2).

$$
\begin{aligned}
& \mathrm{M}=\left|\frac{V_{2}}{V_{1}}\right|=\left|\frac{s^{2} N_{1}}{s^{3} D_{1}+s^{2} D_{2}+s D_{3}+D_{4}}\right| \ldots \ldots \ldots \ldots \\
& D_{1}=\left\{L_{1} L_{2}+\left(L_{1}+L_{2}\right) L_{m}\right\} C, D_{2}=R\left(L_{1}+L_{m}\right) C \\
& D_{3}=\left(L_{2}+L_{m}\right), D_{4}=R, N_{1}=R L_{m} C \\
& \tan \theta=\frac{N_{2}^{\prime} D_{1}^{\prime}-N_{1}^{\prime} D_{2}^{\prime}}{N_{1}^{\prime} D_{1}^{\prime}+N_{2}^{\prime} D_{2}^{\prime}} \ldots \ldots \ldots \ldots \ldots \ldots \\
& D_{1}^{\prime}=-\omega^{2}\left(L_{2}+L_{m}\right) C, D_{2}^{\prime}=\omega R C \\
& N_{1}^{\prime}=\mathrm{R}-\omega^{2} R\left(L_{1}+L_{m}\right) C \\
& N_{2}^{\prime}=-\omega^{3}\left\{L_{1} L_{2}+\left(L_{1}+L_{2}\right) L_{m}\right\} C
\end{aligned}
$$

Parameters $V_{1}$ and $V_{2}$ in Eq. (1) are respectively input and output voltages of LLC resonant tank in Fig. 4. Primary and secondary leakage inductances of the transformer are $L_{1}$ and $L_{2}$ respectively. They are utilized as the resonant inductances in this circuit. The magnetizing inductance of the transformer is $L_{\mathrm{m}}$. The resonant capacitance is $C$ and $R$ means the load resistance in the fundamental frequency analysis. In the case the coupling coefficient of the transformer $k$ is high, the influence of $L_{2}$ on the voltage gain $\mathrm{M}$ is negligible.

Parameters for realizing the connector based on LLC converter topology are shown in Table 2. Figures 5 and 6 show the calculation results of the voltage gain $\mathrm{M}$ and the phase angle $\theta$ characteristics of the impedance in the LLC resonant tank. The voltage gain was drawn when the switching frequency $f_{\mathrm{SW}}$ varied from $100 \mathrm{kHz}$ to $10 \mathrm{MHz}$ in Fig. 5 . The phase angle $\theta$ was also drawn for the switching frequency in Fig. 6. In Fig. 6, the positive value means the impedance has the inductive characteristics because the phase angle of the current has the delay against that of the voltage. The voltage gain and the phase angle were drawn when the load factor changed from $5 \%$ to $200 \%$. Here, the load factor of $100 \%$

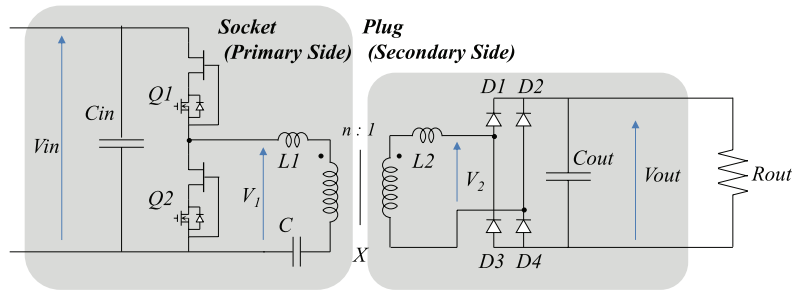

Fig. 4. Circuit configuration of contactless DC connector based on LLC resonant converter topology 
Table 2. Parameters for contactless DC connector based on LLC resonant converter topology

\begin{tabular}{ccc}
\hline Symbol & Meaning & Value \\
\hline$P_{\text {out }}$ & Output power & $1,200 \mathrm{~W}$ \\
$V_{\text {in }}, V_{\text {out }}$ & Input / output voltage & $384 \mathrm{~V} / 192 \mathrm{~V}$ \\
$f_{r L}, f_{r H}$ & Resonant frequency & $220 \mathrm{kHz}, 550 \mathrm{kHz}$ \\
$f_{s w}$ & Switching frequency & $500 \mathrm{kHz}$ \\
$k$ & Coupling coefficient & 0.98 \\
$L_{m}$ & Magnetizing inductance & $19.6 \mu \mathrm{H}$ \\
$L_{1}, L_{2}$ & Resonant inductance & $3.4 \mu \mathrm{H}, 0.4 \mu \mathrm{H}$ \\
$C$ & Resonant capacitance & $22.1 \mathrm{nF}$ \\
$n$ & Turn ratio & 1 \\
\hline
\end{tabular}

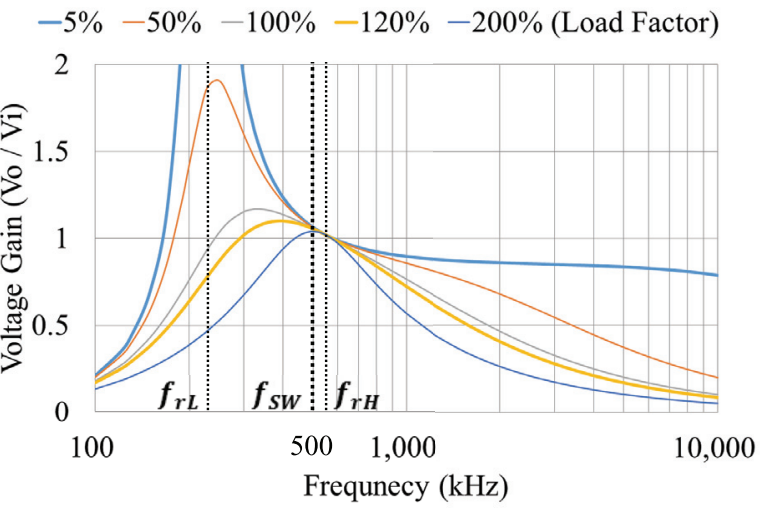

Fig. 5. Voltage gain characteristics of LLC resonant tank for contactless DC connector

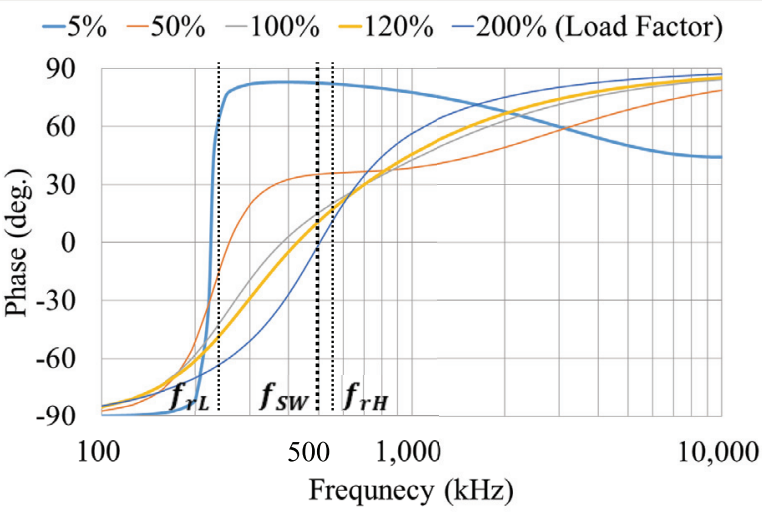

Fig. 6. Phase angle characteristics of LLC resonant tank (positive: inductive, negative: capacitive)

corresponds to the rated output power of $1,200 \mathrm{~W}$.

The frequency $f_{\mathrm{rH}}$ which the voltage gain is independent of the load resistance is set at $550 \mathrm{kHz}$ and the switching frequency is $500 \mathrm{kHz}$ here. Generally, the switching frequency $f_{S W}$ is determined by using the resonant frequencies $f_{r L}$ and $f_{r H}$ in the LLC resonant converter. These resonant frequencies are calculated by using parameters $L_{1}, L_{2}, L_{m}$ and $C$ in the LLC converter circuit as follows.

$$
\begin{aligned}
& f_{r L}=\frac{1}{2 \pi \sqrt{\left(L_{1}+L_{m}\right) \cdot C}} \cong 220 \mathrm{kHz} \ldots \ldots \ldots \ldots \ldots . \\
& f_{r H}=\frac{1}{2 \pi \sqrt{\left(L_{1}+L_{2}\right) \cdot C}} \cong 550 \mathrm{kHz} \ldots \ldots \ldots \ldots \ldots
\end{aligned}
$$

To apply the LLC converter for the DC connector, the output voltage should be independent of the load condition and

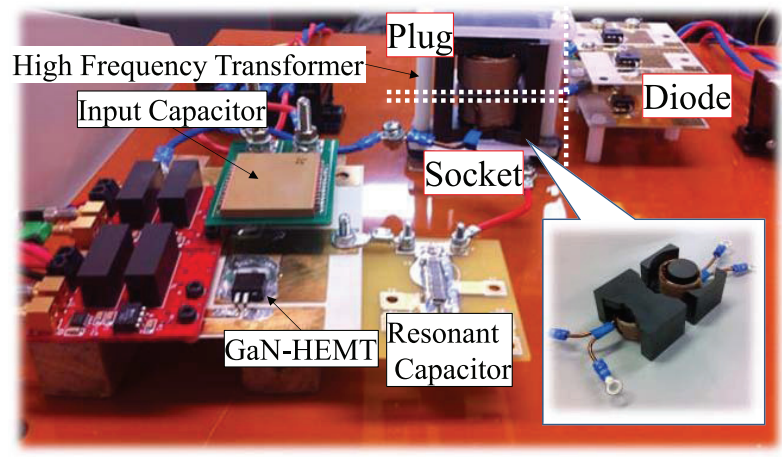

Fig. 7. Experimental apparatus of inductively coupled contactless DC connector

be proportional to its input voltage as the conventional connector with the metal contact. The switching frequency $f_{S W}$ should be set at around the resonant frequency $f_{r H}$.

The soft switching operation has to be achieved in the LLC circuit to realize the highly efficient DC connector. To achieve the ZVS soft switching operation for the main switch, the impedance of the LLC resonant circuit has to be the inductive characteristics (i.e. the phase angle must have the positive value in Fig. 6). The switching frequency $f_{S W}$ should be between resonant frequencies $f_{r L}$ and $f_{r H}$. Additionally, the switching frequency $f_{S W}$ has to be lesser than the resonant frequency $f_{r H}$ to achieve the ZCS soft switching operation for the rectifier diode. Therefore, the switching frequency $f_{S W}$ has been set at $500 \mathrm{kHz}$ in case the resonant frequency $f_{r H}$ is $550 \mathrm{kHz}$.

The magnetizing inductance $L_{\mathrm{m}}$ is determined to suppress the magnetizing current as shown in Eq. (5). Leakage inductances $L_{1}$ and $L_{2}$ are calculated by using $L_{\mathrm{m}}$ and the coupling coefficient of the transformer $k$ as shown in Eq. (6). The resonant capacitor $C$ is designed as the resonant frequency caused by $L_{1}, L_{2}$ and $C$ corresponds to the designated frequency of $550 \mathrm{kHz}$ as Eq. (7). In Fig. 6, these parameters make the impedance characteristics inductive (i.e. positive phase angle) at the switching frequency of $500 \mathrm{kHz}$ under the load factor from $5 \%$ to $120 \%$. This means ZVS can be accomplished at the rated power of $1,200 \mathrm{~W}$.

$$
\begin{aligned}
& V_{L_{m}}=L_{m} \frac{d i_{L_{m}}}{d t} \ldots \ldots \ldots \ldots \ldots \ldots \ldots \ldots \ldots \\
& L_{1}=L_{2}=\frac{1-k}{k} L_{m} \ldots \ldots \ldots \ldots \ldots \\
& 2 \pi f_{r}=\sqrt{\frac{L_{2}+L_{m}}{\left\{L_{1} L_{2}+\left(L_{1}+L_{2}\right) L_{m}\right\} C}} .
\end{aligned}
$$

3.2 Prototype of Contactless DC Connector Using GaN Power Device The prototype of the inductively coupled DC connector was fabricated. Figure 7 shows the experimental apparatus. The output power is $1.2 \mathrm{~kW}$, the input and the output voltages are $384 \mathrm{~V}$ and $192 \mathrm{~V}$, respectively. Circuit parameters were based on Table 2 and components shown in Table 3 were employed to develop the prototype.

GaN-HEMT (600 V, 16 A) from Transphorm was utilized in this experiment. The switching loss energy is smaller than Si power devices and the turn-off energy is independent of the drain current ${ }^{(14)(15)}$. In LLC converter topology, the turnon energy can be eliminated by ZVS and the turn-off energy 
Table 3. Hardware for experiment

\begin{tabular}{|c|c|c|}
\hline Symbol & Meaning & Specification \\
\hline$Q_{1}, Q_{2}$ & GaN-HEMT & $\begin{array}{c}600 \mathrm{~V}, 16 \mathrm{~A}(\text { Transphorm }) \\
R_{\mathrm{ON}}=150 \mathrm{~m} \Omega\end{array}$ \\
\hline$D_{1}-D_{4}$ & SiC-SBD & $\begin{array}{c}600 \mathrm{~V}, 12 \mathrm{~A} \text { (Infineon) } \\
V_{\mathrm{D}}=1.4 \mathrm{~V}\end{array}$ \\
\hline \multirow{2}{*}{$X$} & \multirow{2}{*}{ Transformer } & MC2 (JFE Ferrite) \\
\hline & & PQ 40 PQ 50 \\
\hline$N_{\mathrm{P}}, N_{\mathrm{S}}$ & $\begin{array}{l}\text { Turn No. } \\
\text { of windings }\end{array}$ & $\begin{array}{c}N_{\mathrm{P}}=N_{\mathrm{S}}=12 \quad N_{\mathrm{P}}=N_{\mathrm{S}}=8 \\
\text { Copper }(\rho=1.68 \mu \Omega \cdot \mathrm{cm}) \\
J_{\mathrm{W}}=3 \mathrm{~A} / \mathrm{mm}^{2}\end{array}$ \\
\hline$C_{\text {in, }}, C_{\text {out }}$ & MLCC & $630 \mathrm{~V}, 22 \mu \mathrm{F}$ (Murata) \\
\hline$C$ & MLCC & $1000 \mathrm{~V}, 3.3 \mu \mathrm{F} * 7$ (Murata) \\
\hline
\end{tabular}

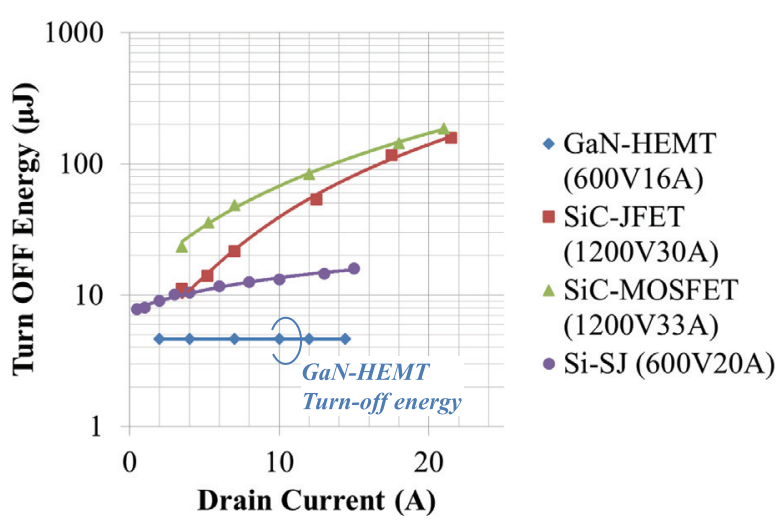

Fig. 8. Measurement results of turn-off energy for GaN-HEMT, Si-SJ MOSFET and SiC-MOSFET

has to be minimized taking the turn-off time for ZVS into account. The constant turn-off energy for the drain current makes the LLC converter design simple. SiC-SBD (600 V, $12 \mathrm{~A})$ from Infineon was also utilized for the rectifier diode. The magnetic core material of MC2 from JFE Ferrite was applied for developing the DC connector. Two cores of PQ40 and PQ50 were employed for the experiment.

Figure 8 shows the measurement result of the turn-off switching energies for GaN-HEMT, SiC-MOSFET and SiSJ (Super Junction) MOSFET. Turn-on switching energies are not shown in Fig. 8 because the ZVS operation in the LLC converter makes the turn-on energy negligible. The doublepulse test was applied to measure the switching loss energies under the inductive load condition. The turn-off switching loss energies for SiC-MOSFET and Si-SJ MOSFET increase as the drain current becomes larger. The aforementioned characteristics which the turn-off energy is independent of the drain current can be seen in the turn-off switching loss energy of only GaN-HEMT.

Figure 9 shows the steady state waveform of the DC connector based on the LLC converter topology under the output power of $1,200 \mathrm{~W}$ and the switching frequency of $500 \mathrm{kHz}$. LLC input voltage means the drain to source voltage of the low-side GaN-HEMT. The LLC input current means the current through the leakage inductance $L_{1}$ and the resonant capacitor $C$. Rectifier input current is through the leakage inductance $L_{2}$. The output voltage of $192 \mathrm{~V}$ was obtained and the LLC input voltage was pure square wave which changed from $0 \mathrm{~V}$ to $384 \mathrm{~V}$. ZVS operation was achieved because the LLC input voltage changed from $384 \mathrm{~V}$ to $0 \mathrm{~V}$ when the LLC

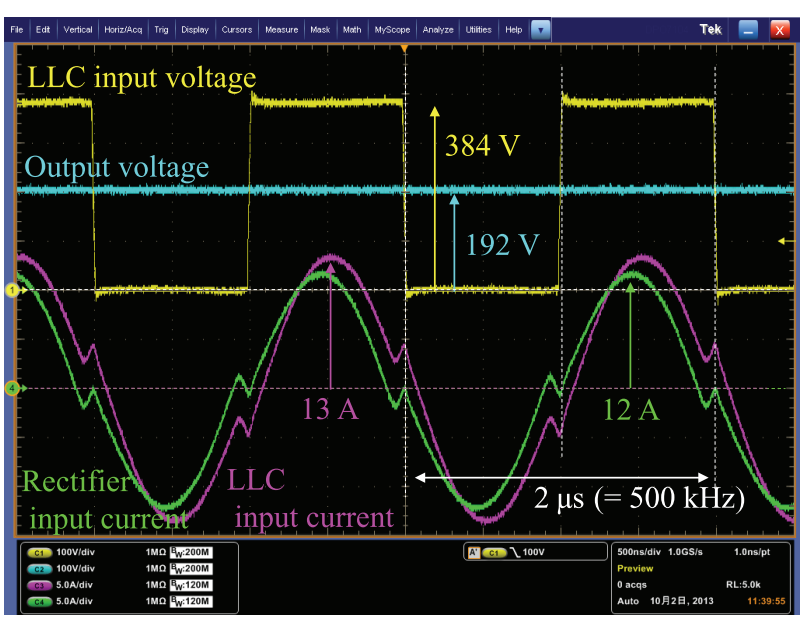

Fig. 9. Steady state waveforms of contactless DC connector under $1,200-\mathrm{W}$ and $500-\mathrm{kHz}$ operation

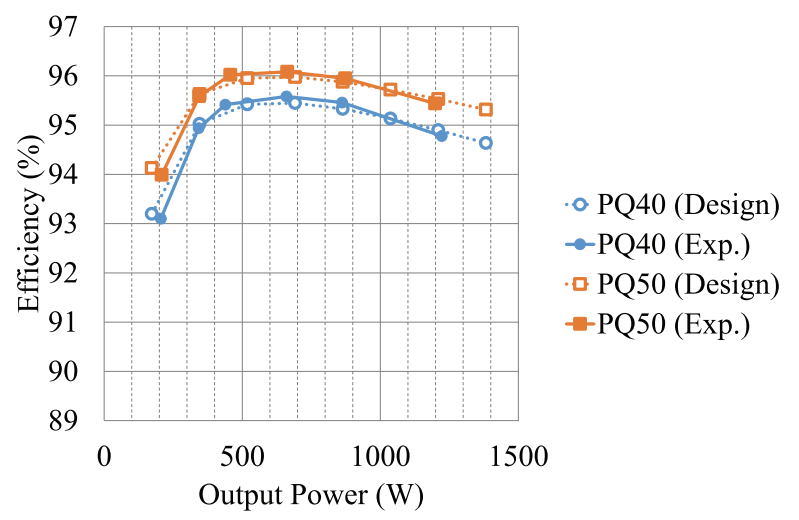

Fig. 10. Measured and estimated efficiencies for DC connector under $500-\mathrm{kHz}$ operation

input current was positive. ZCS was also confirmed because the rectifier input current was nearly equal to $0 \mathrm{~A}$ when the LLC input voltage changed.

Figure 10 shows the measured and the estimated efficiencies for the connector. In this experiment, the maximum conversion efficiency of $96.1 \%$ was confirmed in case PQ50 was utilized and the maximum efficiency of $95.6 \%$ was also obtained in the case of PQ40. These efficiencies were measured by using the power meter WT3000 from YOKOGAWA.

The conversion efficiency was estimated by calculating power losses generated from the transistor $Q$, the transformer $X$, the rectifier diode $D$ and the resonant capacitance $C$ as the following equation.

$$
\begin{aligned}
P_{T}= & P_{Q}+P_{X}+P_{C}+P_{D} \\
= & \left(P_{C O N D}+P_{O F F}\right)+\left(P_{C u}+P_{C O R E}\right)+P_{C}+P_{D} \\
= & \left(R_{O N} \cdot I^{2}+f_{S W} \cdot E_{O F F}\right) \\
& +\left\{\left(R_{W P}+R_{W S}\right) \cdot I^{2}+f_{S W} \cdot E_{C O R E}\right\} \\
& +R_{C} \cdot I^{2}+V_{D} \cdot I \ldots \ldots \ldots \ldots \ldots \ldots \ldots \ldots
\end{aligned}
$$

The total power loss is $P_{\mathrm{T}}$. The power loss generated from transistors, the transformer, the capacitor and the diode are $P_{\mathrm{Q}}, P_{\mathrm{X}}, P_{\mathrm{C}}$ and $P_{\mathrm{D}}$, respectively. The power losses from transistor $P_{\mathrm{Q}}$ consist of the conduction loss $P_{\mathrm{COND}}$ and the turnoff switching loss $P_{\mathrm{OFF}}$. The conduction loss of the transistor $P_{\mathrm{COND}}$ depends on the on-resistance $R_{\mathrm{ON}}$ and the converter 


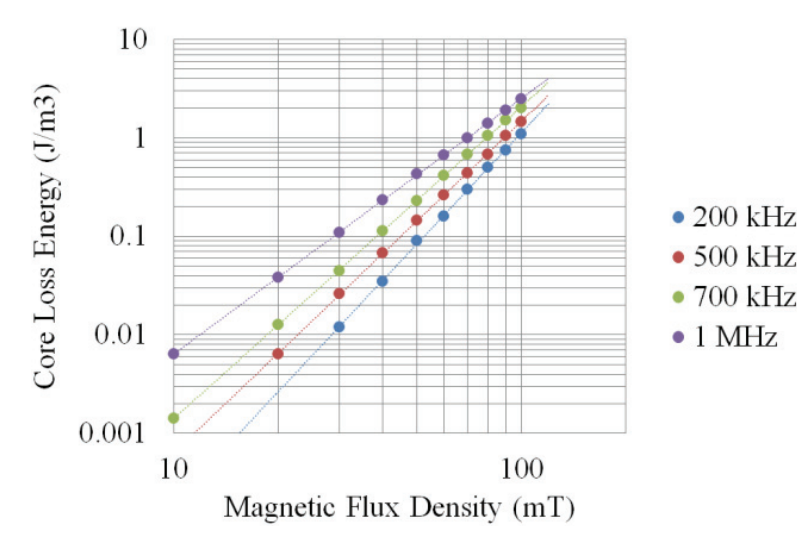

Fig. 11. Core loss energy characteristics of magnetic core material

resonant current $I$. The turn-off switching loss $P_{\mathrm{OFF}}$ is determined by the operating switching frequency $f_{\mathrm{SW}}$ and the turn-off energy $E_{\mathrm{OFF}}$ as shown in Fig. 8. The losses from the transformer consists of the winding copper loss $P_{\mathrm{Cu}}$ and the core loss $P_{\text {CORE }}$. The copper loss $P_{\mathrm{Cu}}$ depends on the winding resistances $R_{\mathrm{WP}}, R_{\mathrm{WS}}$ and the resonant current $I$. The core loss is calculated by using the frequency $f_{\mathrm{SW}}$ and the core loss energy $E_{\mathrm{CORE}}$ in Fig. 11 . The resistance $R_{\mathrm{C}}$ means the equivalent series resistance (ESR) of the resonant capacitor $C$ and the voltage $V_{\mathrm{D}}$ shows the forward voltage drop of the rectifier diode $D$. Here, the current $I$ through the resonant circuit is commonly utilized to estimate the losses $P_{\mathrm{Q}}, P_{\mathrm{X}}, P_{\mathrm{C}}$ and $P_{\mathrm{D}}$ because the turn ratio of the transformer is 1 .

The static parameters of the semiconductor power device are given from the published datasheet and they are shown in Table 3. The winding resistances of the transformer $R_{\mathrm{WP}}$, $R_{\mathrm{WS}}$ and the equivalent series resistance (ESR) of the resonant capacitor $R_{\mathrm{C}}$ were measured by using impedance analyzer PSM1735 from N4L. These impedances at $500 \mathrm{kHz}$ were utilized to calculate winding losses. The winding resistance and the ESR were $1.5 \mathrm{~m} \Omega / \mathrm{cm}$ and $33 \mathrm{~m} \Omega$ respectively at the frequency. The core loss of the transformer $P_{\text {CORE }}$ is calculated by using the core loss energy per unit volume $E_{\mathrm{CORE}}$ taking the magnetic flux density $\Delta \mathrm{B}$, the switching frequency $f_{\mathrm{SW}}$ and the core dimensions into account. The core loss energy $E_{\mathrm{CORE}}$ in this experiment is shown in Fig. 11 and the approximation formulae have been developed to estimate the loss.

The magnetic flux density $\Delta \mathrm{B}$ is calculated by using the turn number at the primary side of the transformer $N_{\mathrm{P}}$, the cross section area of the magnetic core $S_{\mathrm{e}}$, the injected voltage to the transformer $V_{\mathrm{X}}$ and the injected time determined by the switching frequency $T_{\mathrm{ON}}$. Two magnetic cores of PQ40 and PQ50 have been applied for the experiment. The turn number of the winding has been selected as the magnetic flux density has been smaller than $100 \mathrm{mT}$ for both magnetic cores.

In the case of PQ40, the cross section area of the transformer core $S_{\mathrm{e}}$ was $201 \mathrm{~mm}^{2}$ from the published datasheet and the magnetic flux density $\Delta \mathrm{B}$ was calculated to be $79.6 \mathrm{mT}$ as the following equation.

$$
\Delta \mathrm{B}_{P Q 40}=\frac{1}{N_{P} \cdot S_{e}} \int_{0}^{T_{O N}} V_{X} \mathrm{dt}=\frac{384 V / 2}{12 \cdot 201 \mathrm{~mm}^{2}} \cdot \frac{1}{500 \mathrm{kHz} \cdot 2}
$$

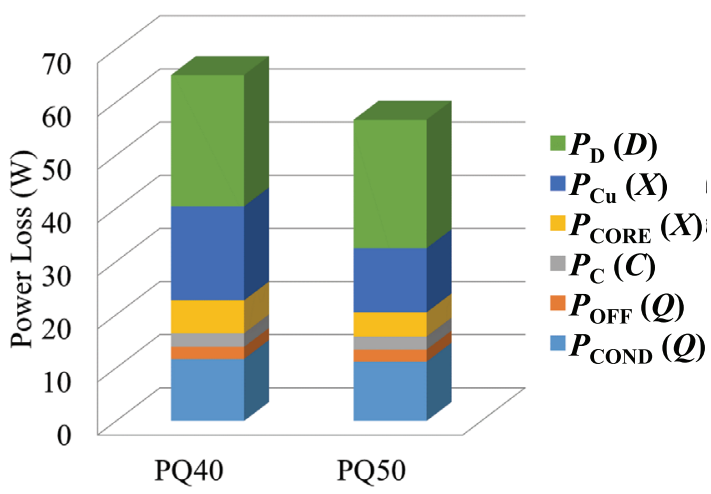

Fig. 12. Power loss distribution for $1,200-W$ DC connector under $500-\mathrm{kHz}$ operation

$$
=79.6 \mathrm{mT}
$$

In the case of PQ50, the cross section area of the transformer core $S_{\mathrm{e}}$ was $328 \mathrm{~mm}^{2}$ and the magnetic flux density $\Delta \mathrm{B}$ was calculated to be $73.2 \mathrm{mT}$.

$$
\begin{aligned}
\Delta \mathrm{B}_{P Q 50} & =\frac{1}{N_{P} \cdot S_{e}} \int_{0}^{T_{O N}} V_{X} \mathrm{dt}=\frac{384 V / 2}{8 \cdot 328 \mathrm{~mm}^{2}} \cdot \frac{1}{500 \mathrm{kHz} \cdot 2} \\
& =73.2 \mathrm{mT} \cdots \ldots \ldots \ldots \ldots \ldots \ldots \ldots \ldots \ldots \ldots \ldots \ldots \ldots \ldots
\end{aligned}
$$

The estimated efficiencies from $300 \mathrm{~W}$ to $1,200 \mathrm{~W}$ had good agreement with the measurement result as shown in Fig. 10. Figure 12 shows the power loss distributions for two magnetic cores of PQ40 and PQ50 under 1,200-W and 500$\mathrm{kHz}$ operation. Power losses calculated by using Eq. (8) are shown in this figure. The legends of $P_{\mathrm{COND}}(Q)$ and $P_{\mathrm{OFF}}$ $(Q)$ mean the conduction loss and the turn-off switching loss from the transistor $Q$ respectively. The legends of $P_{\mathrm{Cu}}(X)$ and $P_{\mathrm{CORE}}(X)$ are respectively the winding loss and the core loss from the transformer $X$. The $P_{\mathrm{C}}(C)$ means the loss caused by the ESR in the resonant capacitor $\mathrm{C}$ and the $P_{\mathrm{D}}$ $(D)$ means the loss from the rectifier diode $D$.

The conversion efficiency of the connector using PQ40 was lower than the efficiency of PQ50. The core loss generated from the transformer using PQ40 was larger than that of PQ50 because of larger magnetic flux density taking the core volume into account. The winding loss of the transformer using PQ 40 was also larger because the winding length was totally longer than that of PQ50 taking the turn number and the winding radius into account.

The power loss generated from the transformer was influential in the total converter loss as shown in Fig. 12. The transformer has some controllable structural parameters as the core dimensions and the turn numbers of the windings. These parameters affect not only the efficiency but also the power density of the connector. It is important to evaluate the influence of the transformer parameters on the connector volume for achieving higher power density.

\section{Design Consideration for $10 \mathrm{~W} / \mathrm{cm}^{3}$ Contact- less DC Connector}

The fundamental electric performance has been confirmed by fabricating the $1.2-\mathrm{kW}$ breadboard with the maximum efficiency of $96.1 \%$ under $500-\mathrm{kHz}$ operation. High efficiency and ultra-compact DC connector with more than $10 \mathrm{~W} / \mathrm{cm}^{3}$ is necessary to realize high-power-density $380-\mathrm{V}$ DC dis- 
tribution system as shown in Table 1 . In this chapter, the feasibility of the $10 \mathrm{~W} / \mathrm{cm}^{3}$ contactless DC connector is investigated through the design consideration.

The design methodology for high-power-density converters has been proposed ${ }^{(16)-(18)}$. The relationship between the power density and the efficiency is essential to evaluate the barrier of power converter performance. Authors have already proposed the design methodology for realizing highpower-density converter. The parameter design to maximize the power density has been also conducted for the DC-DC converter drawing relationship between the power density and the conversion efficiency using power loss limit model for the novel power device and the loss map for the magnetic core material which estimate exact power losses under real circuit operation condition ${ }^{(18)-(21)}$. Here, the above design methodology is applied for the $1.2-\mathrm{kW} 384 \mathrm{~V}-192 \mathrm{~V}$ contactless DC connector and the possible power density is estimated taking the influences of parameters related to the transformer into account.

4.1 Relationship between Power Density and Conversion Efficiency The power density barrier under the ideal conditions is estimated for the $1.2-\mathrm{kW} 384 \mathrm{~V}-192 \mathrm{~V}$ experimental breadboard in the previous chapter to evaluate the feasibility of the $10 \mathrm{~W} / \mathrm{cm}^{3}$ contactless DC connector. Ideal conditions to estimate the barrier means the following postulations.

- Semiconductor power devices, gate drivers and auxiliary circuits can be constructed by the highly integrated power modules although discrete power devices and auxiliary components are utilized in the experiment in Fig. 7.

- Power density is calculated by the total amount of components' pure volumes. Interspaces among components are not taken into account to estimate the power density.

Highly integrated power modules are now available and the progress of the integration technology makes the effect of the interspace negligible. Through the postulations, the influence of the design parameters related to the transformer can be discussed simply and the potential of the connector using GaN power transistor and MC2 magnetic core can be seen.

The power density of the connector $D_{\mathrm{P}}$ and the efficiency $\eta$ are estimated simply by using the following equations.

$$
\begin{aligned}
D_{P}\left[\frac{\mathrm{W}}{\mathrm{cm}^{3}}\right] & =\frac{P_{\text {OUT }}[\mathrm{W}]}{V o_{T}\left[\mathrm{~cm}^{3}\right]} \\
& =\frac{P_{O U T}}{V o_{M}+V o_{X}+V o_{C}+V o_{H S}\left(P_{T}\right)} \cdots \ldots \\
\eta[\%] & =\frac{P_{O U T}}{P_{\text {OUT }}+P_{T}} \times 100 \ldots \ldots \ldots \ldots \ldots
\end{aligned}
$$

The output power of the connector is $P_{\text {OUT }}$ and the total volume of the connector is $V_{\mathrm{OT}}$. The total volume $V_{\mathrm{OT}}$ consists of volumes of the power module $V_{\mathrm{OM}}$ including semiconductor power devices and the auxiliary circuit, the transformer $V_{\mathrm{OX}}$, the resonant capacitor $V_{\mathrm{OC}}$ and the heat sink $V_{\mathrm{OHS}}$. The heat sink volume $V_{\mathrm{OHS}}$ is simply estimated by using the total power loss $P_{\mathrm{T}}$ and the heat dissipation efficiency $k_{\mathrm{HS}}{ }^{(22)}$.

The total power loss $P_{\mathrm{T}}$ consists of the loss from the main switch $P_{\mathrm{Q}}$, the transformer loss $P_{\mathrm{X}}$, the capacitor loss $P_{\mathrm{C}}$ and

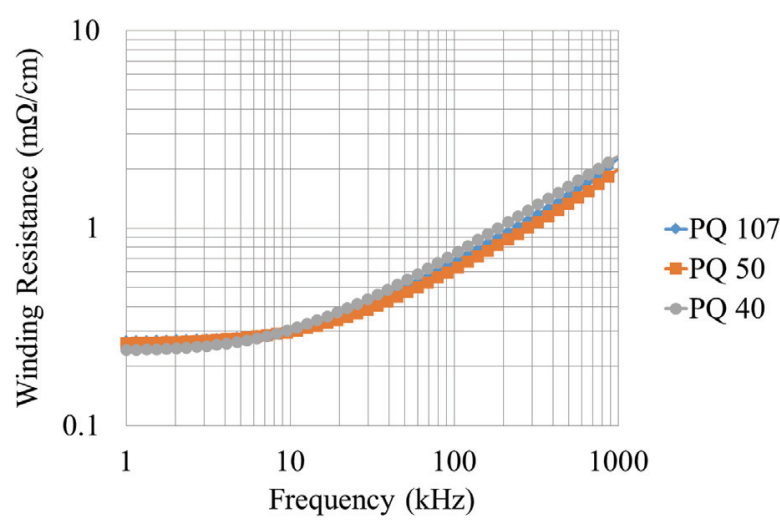

Fig. 13. Measurement result of winding resistance per $1 \mathrm{~cm}$ in transformer using PQ core

Table 4. Parameters for design consideration.

\begin{tabular}{cccc}
\hline Parameter & Min. & Max. & Step \\
\hline Switching frequency & $100 \mathrm{kHz}$ & $1 \mathrm{MHz}$ & $100 \mathrm{kHz}$ \\
Magnetic Flux Density & $50 \mathrm{mT}$ & $150 \mathrm{mT}$ & $10 \mathrm{mT}$ \\
Transformer Core Shape & PQ20 & PQ50 & - \\
Core Width & $20.0 \mathrm{~mm}$ & $50.0 \mathrm{~mm}$ & $1.0 \mathrm{~mm}$ \\
Core Depth & $14.0 \mathrm{~mm}$ & $32.0 \mathrm{~mm}$ & - \\
Core Height & $20.0 \mathrm{~mm}$ & $50.0 \mathrm{~mm}$ & - \\
Heat Dissipation Efficiency & & $0.45 \mathrm{~W} / \mathrm{cm}^{3}$ & \\
\hline
\end{tabular}

the rectifier diode loss $P_{\mathrm{D}}$ as shown in Eq. (8). The heat sink volume $V_{\mathrm{OHS}}$ is calculated as follows. Here, electrical parameters for semiconductor power devices were fixed because the output power of the designed connector was 1,200 W. Hardware shown in Table 3 were assumed and their parameters were obtained from the published datasheet.

$$
\begin{aligned}
V o_{H S}\left[\mathrm{~cm}^{3}\right] & =\frac{P_{T}[W]}{k_{H S}\left[\mathrm{~W} / \mathrm{cm}^{3}\right]}=\frac{P_{Q}+P_{X}+P_{C}+P_{D}}{k_{H S}} \\
& \ldots \ldots \ldots \ldots \ldots \ldots \ldots \\
P_{Q}[W] & =\left(R_{O N} \cdot I^{2}+f_{S W} \cdot E_{O F F}\right) \\
P_{X}[W] & =\left\{\left(R_{W P}+R_{W S}\right) \cdot I^{2}+f_{S W} \cdot E_{C O R E}\right\} \\
P_{C}[W] & =R_{C} \cdot I^{2} \\
P_{D}[W] & =V_{D} \cdot I
\end{aligned}
$$

The current density $J_{\mathrm{W}}$ of the primary and the secondary solenoidal copper windings for the transformer was also fixed at $3.0 \mathrm{~A} / \mathrm{mm}^{2}$ because of the constant output power. In this case, the winding resistances per unit length were approximately equal for different dimensions of PQ magnetic core taking the influences of the skin effect and the proximity effect into account as shown in Fig. 13. Figure 13 shows the measurement result of the winding resistances per $1 \mathrm{~cm}$ using the LCR meter PSM1735 from N4L in case the magnetic core shapes of PQ 40, PQ 50 and PQ 107 were employed to develop the transformer windings for the connector. The winding resistances $R_{\mathrm{WP}}$ and $R_{\mathrm{WS}}$ of the transformer were calculated by using the measurement result in this figure.

Table 4 shows variable parameters for this design. The magnetic flux density $\Delta \mathrm{B}$, the core dimensions of the transformer and the switching frequency $f_{\mathrm{SW}}$ were varied. Parameters related to the transformer were mainly varied because the power loss generated from the transformer was influential in the experiment. Heat dissipation efficiency $k_{\mathrm{HS}}$ was 


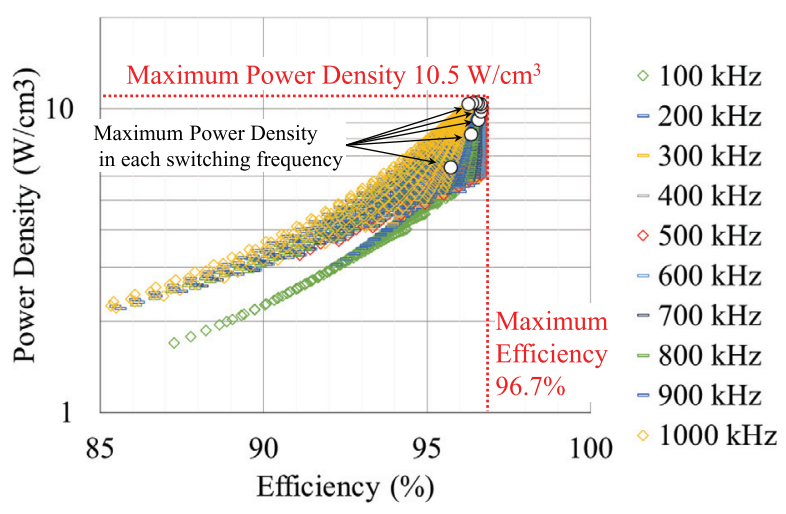

Fig. 14. Relationship between power density and efficiency for 1.2-kW $384 \mathrm{~V}-192 \mathrm{~V}$ Connector

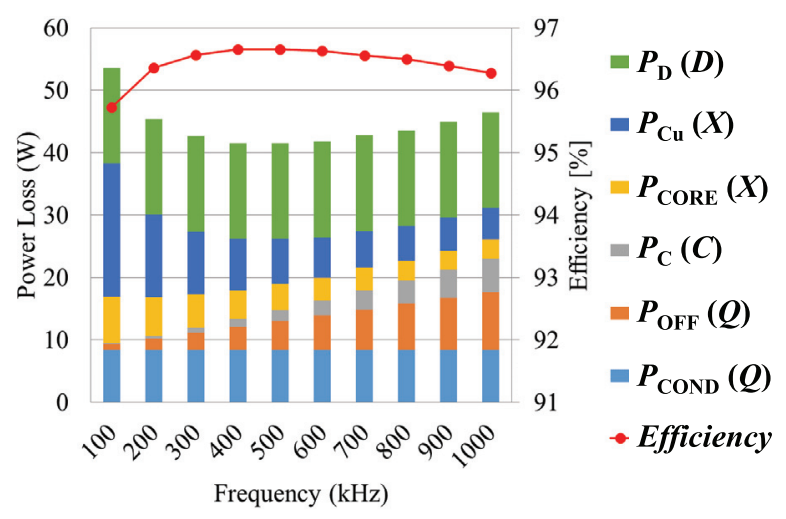

Fig. 15. Estimated power loss and efficiency for 1.2kW 384 V-192 V DC Connector

$0.45 \mathrm{~W} / \mathrm{cm}^{3}$ taking the cooling condition of forced air cooling in data center into account.

To change the core shape, just the core width is controlled here. The core depth and the core height were proportion to the core width based on the determined core shape. The core shape of the transformer was fixed here and the PQ type magnetic core was applied for the connector to achieve the high coupling coefficient (e.g. larger than 0.9). Although the leakage inductances $L_{1}$ and $L_{2}$ vary in case that the core dimensions changes, they are relatively smaller than the required resonant inductance. The inductance value for the resonant circuit can be controlled by installing the external inductance. In this design, the effect of the leakage inductance on the resonant circuit condition is negligible because of the high coupling coefficient using the magnetic core transformer.

Figure 14 shows the relationship between the power density and the efficiency for design parameters in Table 4. Totally 3000 samples (10 switching frequencies, 10 magnetic flux densities and 30 transformer core shapes) were plotted in this figure. This figure means that the power density and the efficiency are limited to $10.5 \mathrm{~W} / \mathrm{cm}^{3}$ and $96.7 \%$ respectively in the case of design parameters shown in Table 4.

Figure 15 shows the estimated efficiency to maximize the power density $D_{P}$ and the loss distribution for varied switching frequencies from $100 \mathrm{kHz}$ to $1,000 \mathrm{kHz}$. Power losses generated from the main switch $Q$, the rectifier diode $D$, the transformer $X$ and the resonant capacitor $C$ are shown here. The maximum efficiency of $96.7 \%$ appears at the frequency of $400 \mathrm{kHz}$ and $500 \mathrm{kHz}$.

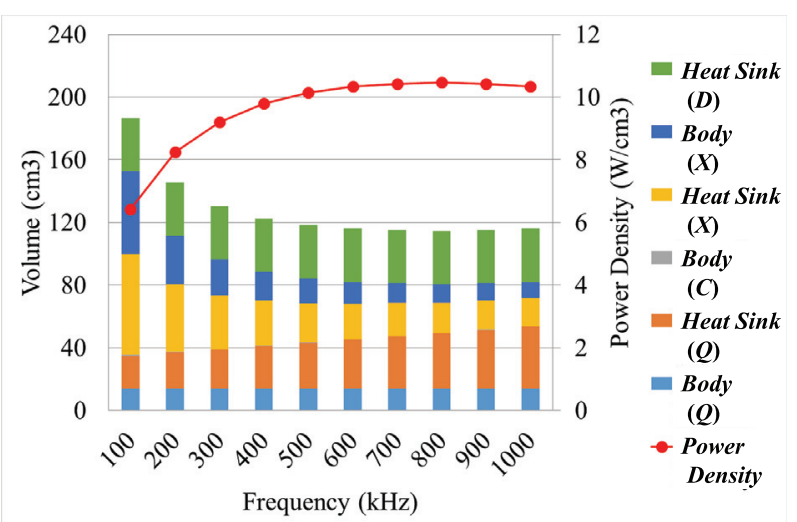

Fig. 16. Estimated volume and power density for 1.2kW 384 V-192 V DC Connector

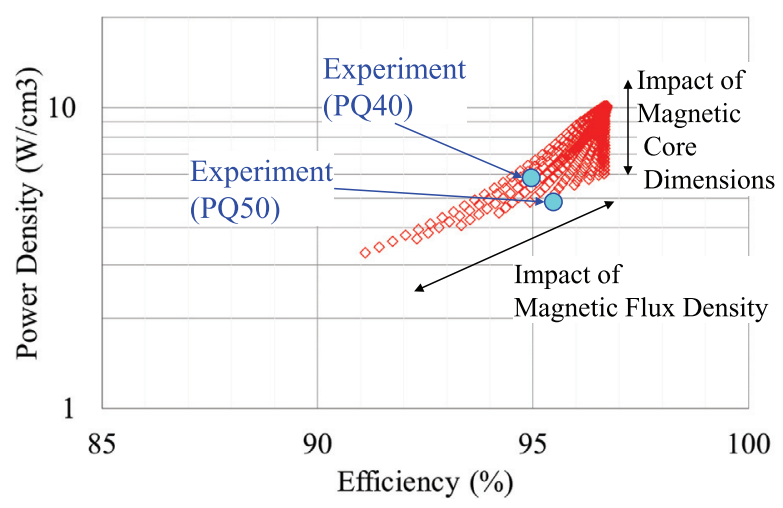

Fig. 17. Calculated power density and efficiency for 1.2-kW 384 V-192 V Connector under 500-kHz operation

Figure 16 shows the detailed volume distribution and the power density. Body $(Q)$, Body $(X)$ and Body $(C)$ in this figure mean component's volumes of the power module $V_{\mathrm{OM}}$, the transformer $V_{\mathrm{OX}}$ and the resonant capacitor $V_{\mathrm{OC}}$ in Eq. (11) respectively. Heat sink volumes caused by the power losses from the main switch $Q$, the rectifier diode $D$ and the transformer $X$ are also shown. Here, the volume of power module for a socket and a plug was set at $14.2 \mathrm{~cm}^{3}$ $(=3.8 \mathrm{~cm} \times 3.4 \mathrm{~cm} \times 0.55 \mathrm{~cm} \times 2)$ taking the commercially available power module for $600 \mathrm{~V} 15 \mathrm{~A}$ (e.g. DIP-IPM from MITSUBISHI) into account. The maximum power density of $10.5 \mathrm{~W} / \mathrm{cm}^{3}$ appears around the frequency of $800 \mathrm{kHz}$.

4.2 Performance of Experimental Breadboard and Approach to Realize $10 \mathrm{~W} / \mathrm{cm}^{3}$ Contactless DC Connector Figure 17 shows the calculation result of the power density and the conversion efficiency for the $1.2-\mathrm{kW}, 384 \mathrm{~V}-$ $192 \mathrm{~V}$ contactless DC connector under the condition that the magnetic flux density varied from $50 \mathrm{mT}$ to $150 \mathrm{mT}$, the core width varied from $20.0 \mathrm{~mm}$ to $50.0 \mathrm{~mm}$ and the switching frequency was fixed at $500 \mathrm{kHz}$. The calculation result for the frequency of $500 \mathrm{~Hz}$ has been extracted from Fig. 14 to evaluate the performance of the experimental breadboard. The magnetic flux density $\Delta \mathrm{B}$ affects the efficiency and the magnetic core dimensions determines the connector total volume mainly. The optimal core dimension exists in each operating magnetic flux density and smaller magnetic core tends to achieve higher power density. The power density and the efficiency are limited to $10.1 \mathrm{~W} / \mathrm{cm}^{3}$ and $96.6 \%$ respectively 
under $500-\mathrm{kHz}$ operation.

Experimental results shown in the previous section have been also plotted on Fig. 17. The experimental result using the core shape of PQ40 was plotted at the coordinate of the power density of $5.7 \mathrm{~W} / \mathrm{cm}^{3}$ and the efficiency of $94.8 \%$ at $1,200-\mathrm{W}$ output power. The ideal power density of the experiment was calculated by using the following equation, taking the heat dissipation efficiency $k_{\mathrm{HS}}$ for the heat sink volume into account. Here, the total transformer volume $V_{\mathrm{OX}}$ by using PQ40 was $51.2 \mathrm{~cm}^{3}(=4 \mathrm{~cm} \times 4 \mathrm{~cm} \times 3.2 \mathrm{~cm})$ and the influence of the resonant capacitor $C$ was not considered because its volume was negligible.

$$
5.7 \mathrm{~W} / \mathrm{cm}^{3}=\frac{1,200 \mathrm{~W}}{14.2 \mathrm{~cm}^{3}+51.2 \mathrm{~cm}^{3}+\frac{65.8 \mathrm{~W}}{0.45 \mathrm{~W} / \mathrm{cm}^{3}}}
$$

The experimental result using PQ 50 was also plotted at the coordinate of the power density of $4.9 \mathrm{~W} / \mathrm{cm}^{3}$ and the efficiency of $95.4 \%$ at $1,200 \mathrm{~W}$. The ideal power density was calculated as follows with the transformer volume $V_{\mathrm{OX}}$ of $100 \mathrm{~cm}^{3}(=5 \mathrm{~cm} \times 5 \mathrm{~cm} \times 4 \mathrm{~cm})$.

$$
4.9 \mathrm{~W} / \mathrm{cm}^{3}=\frac{1,200 \mathrm{~W}}{14.2 \mathrm{~cm}^{3}+100 \mathrm{~cm}^{3}+\frac{57.9 \mathrm{~W}}{0.45 \mathrm{~W} / \mathrm{cm}^{3}}}
$$$$
\text { ................ (15) }
$$

Relationships between the power density and the efficiency were shown for two experimental results using PQ40 and PQ50. The connector using smaller magnetic core of PQ40 has the potential to achieve higher power density compared with the result using PQ50. However, the efficiency decreases because of the higher operating magnetic flux density. This figure means that the two experimental results are not on the design limit and the parameter design of the transformer has the potential to increase the power density of the connector. From Figs. 16 and 17, the transformer volume is around $15.8 \mathrm{~cm}^{3}$ and the utilization of PQ26 is assumed to realize the maximum power density of $10.1 \mathrm{~W} / \mathrm{cm}^{3}$ under $500-\mathrm{kHz}$ operation.

Figure 18 shows the illustrations of the DC connectors. The connector for DC 380-V DC distribution system, the contactless DC connector from the experimental breadboard and the connector from design consideration to achieve $10 \mathrm{~W} / \mathrm{cm}^{3}$ were shown. Discrete components with PQ40 magnetic core utilized in the experiment were arranged for the illustration of the experimental breadboard. The transformer from the optimal design in Figs. 16 and 17 were utilized to draw the illustration for design consideration to achieve $10 \mathrm{~W} / \mathrm{cm}^{3}$. The magnetic core shape of PQ26 was assumed and the highly integrated power modules was also considered for the illustration. From Fig. 18, the transformer design has the potential to improve the power density of the contactless DC connector. The power density of $10 \mathrm{~W} / \mathrm{cm}^{3}$ will be accomplished not only by the optimal design of the transformer but also the aforementioned postulations for the integration technology. The contactless DC connector using $\mathrm{GaN}$ transistors and MC2 magnetic core material will contribute to realizing future high-power-density 380-V DC distribution system.

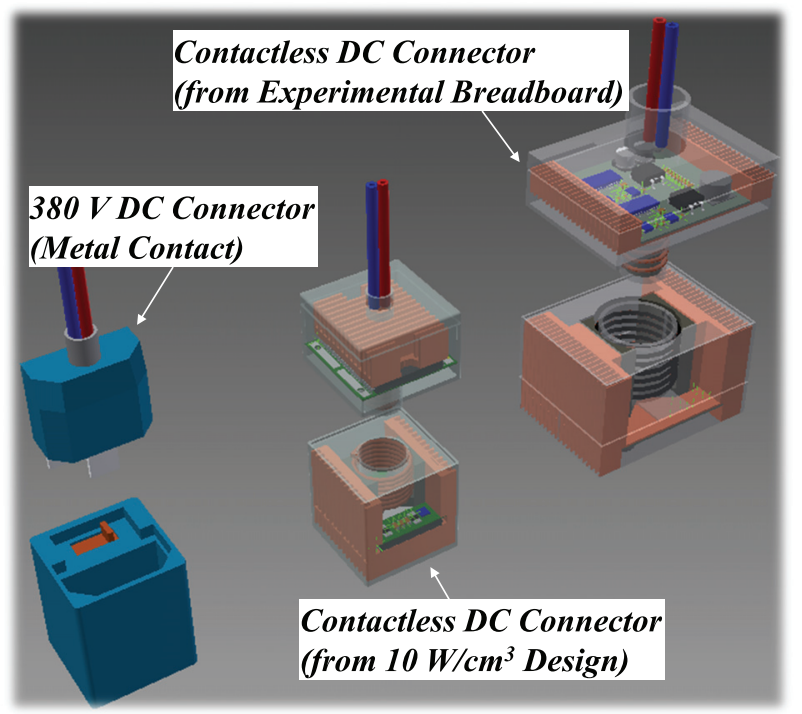

Fig. 18. Illustrations of 380-V DC connectors with metal contact, contactless DC connector from experimental breadboard and connector from $10 \mathrm{~W} / \mathrm{cm}^{3}$ design.

\section{Conclusions}

The contactless DC connector has been proposed to realize the future high-power-density 380-V DC power feeding system in data centers. The LLC resonant circuit topology was applied to realize the short-range inductively coupled contactless power transfer. The prototype of 1,200-W $384 \mathrm{~V}-$ 192 V DC connector was fabricated using GaN-HEMT and the efficiency of $96.1 \%$ was achieved. The design consideration for the contactless DC connector was also conducted, and the potential to achieve $10 \mathrm{~W} / \mathrm{cm}^{3}$ was shown. This means the proposed contactless DC connector will be realized in the same volume as the conventional DC connector. This contributes to realizing future high-power-density DC distribution system.

\section{Acknowledgment}

Authors would like to thank Mr. A. Matsumoto at NTT Facilities, Inc. for the support and fruitful discussions of the next-generation 380-V DC distribution system. A part of this work has been carried out in the collaborative research with NTT Facilities, Inc.

\section{References}

( 1 ) R.R. Schmidt, C. Belady, A. Classen, T. Davidson, M.K. Herrlin, S. Novotny, and R. Perry: "Evolution of Data Center Environmental Guidelines", ASHRAE Transactions, Vol.110, Part1, pp.559-566 (2004)

(2) A. Fukui, T. Takeda, K. Hirose, and M. Yamasaki: "HVDC Power Distribution Systems for Telecom Sites and Data Centers", Proceedings of the 2010 International Power Electronics Conference (IPEC), Sapporo, Japan (2010)

( 3 ) Y. Sugiyama: "Green ICT toward Low Carbon Society-Green R\&D Activities in NTT", Proceedings of 4th International Workshop on Green Communications, Kyoto, Japan (2011)

( 4 ) B. Eckardt, A. Hofmann, S. Zeltner, and M. Maerz: "Automotive powertrain DC/DC converter with $25 \mathrm{~kW} / \mathrm{dm}^{3}$ by using SiC diodes", Proceedings of 4th International Conference on Integrated Power Systems (CIPS), Naples, Italy, 2006.

( 5 ) J. Sun, M. Xu, Y. Ying, and F.C. Lee: "High power density, high efficiency system two-stage power architecture for laptop computers", Proceedings of 
37th IEEE Power Electronics Specialists Conference (PESC), Jeju, Korea, pp.231-237 (2006)

( 6 ) U. Badstuebner, J. Biela, and J.W. Kolar: "An optimized, 99\% efficient, $5 \mathrm{~kW}$, phase-shift PWM DC-DC converter for data centers and telecom applications", Proceedings of the International Power Electronics Conference (IPEC), Sapporo, Japan, pp.626-634 (2010)

( 7 ) D.A.G. Pedder, A.D. Brown, and J.A. Skinner: "A Contactless Electrical Energy Transmission System”, IEEE Trans. Ind. Electron., Vol.46, No.1, FEB. pp.23-30 (1999)

( 8 ) E. Kim, S Kang, K. Yoon, and Y. Kim: "A Contactless Power Supply for Photovoltaic Power Generation System", Proceedings of Applied Power Electronics Conference and Exposition (APEC), Texas, the U.S., pp.1910-1913 (2008)

( 9 ) Y. Hayashi: "High Power Density Rectifier for Highly Efficient Future DC Distribution System", Journal of Electrical Engineering Research (EER), Electrical Engineering Publishing Company, Vol.1, No.3 (2013)

(10) http://www.vicorpower.com/

(11) Y. Hayashi: "Multi-converter approach to higher power density DC-DC converter for 380 V DC distribution system", Journal of Energy and Power Engineering (JEPE), Vol.7, No.7, pp.1371-1343 (2013)

(12) T.S. Chan and C. Chern-Lin: "LLC resonant converter for wireless energy transmission system with PLL control”, Proceedings of IEEE International Conference on Sustainable Energy Technologies (ICSET), Singapore (2008)

(13) Y. Yang: "A Contactless Charger with LLC Tank and Microcontroller", Proceedings of s the 35th Annual Conference of the IEEE Industrial Electronics Society (IECON), Porto, Portugal (2009)

(14) Z. Liu, X. Huang, F.C. Lee, and Q. Li: "Simulation Model Development and Verification for High Voltage GaN HEMT in Cascode Structure", Proceedings of the IEEE Energy Conversion Congress and Exposition (ECCE), Denver, U.S. (2013)

(15) W. Zhang, Z. Xu, Z. Zhang, F. Wang, L.M. Tolbert, and B.J. Blalock: "Evaluation of $600 \mathrm{~V}$ Cascode GaN HEMT in Device Characterization and AllGaN-Based LLC Resonant Converter", Proceedings of the IEEE Energy Conversion Congress and Exposition (ECCE), Denver, U.S. (2013)

(16) J.W. Kolar, J. Biela, and J. Miniböck: "Exploring the Pareto Front of Multi-Objective Single-Phase PFC Rectifier Design Optimization -99.2\% Efficiency vs. $7 \mathrm{~kW} / \mathrm{din} 3$ Power Density", Proceedings of the IEEE 6th International Power Electronics and Motion Control Conference (IPEMC), Wuhan, China (2009)

(17) H. Ohashi: "Research activities of the power electronics research center with special focus on wide band gap materials", Proceedings of 4th International Conference on Integrated Power Systems (CIPS2006), Naples, Italy (2006)

(18) Y. Hayashi, K. Takao, and H. Ohashi: "Fundamental Study of High Density DC/DC Converter Design based on Sensitivity Analysis", Proceedings of the International Telecommunications Energy Conference (INTELEC), Incheon, Korea (2009)

(19) K. Takao, H. Irokawa, Y. Hayashi, and H. Ohashi: "Novel exact power loss design method for high output power density converter", Proceedings of 37th IEEE Power Electronics Specialists Conference (PESC), pp.2651-2655, Jeju, Korea (2006)

(20) S. Iyasu, T. Shimizu, and K. Ishii: "A Novel Inductor Loss Calculation Method on Power Converters Based on Dynamic Minor Loop", IEEJ Trans. IA, Vol.126-D, No.7, pp.1028-1034 (2006)
(21) K. Kim and T. Shimizu: "Dynamic Iron Loss Measurement Method for an AC Filter Inductor on a PWM Inverter", Proceedings of the 12th European Conference on Power Electronics and Applications (EPE) 2007, Aalborg, Denmark (2007)

(22) M. Tsukuda, I. Omura, T. Domon, W. Saito, and T. Ogura: "Demonstration of High Output Power Density $(30 \mathrm{~W} / \mathrm{cc}$ ) Converter using $600 \mathrm{~V}$ SiC-SBD and Low Impedance Gate Driver", Proceedings of the 2005 International Power Electronics Conference (IPEC), Niigata, Japan (2005)

Yusuke Hayashi (Member) completed a postdoctoral course in engineering at Osaka University Graduate School in 2004.

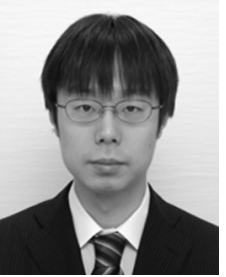
In April 2004, he joined the AIST Power Electronics Research Center, in April 2009 he joined NTT Facilities, and since May 2013 he has been with Osaka University. He is engaged in the research and development of the power quality control in the distribution system and the development of the design methodology for high power density converter using $\mathrm{SiC}$ and $\mathrm{GaN}$ power devices. Currently, he is mainly engaged in the development of the high power density DC power supply for $380 \mathrm{~V}$ DC distribution system.

Hajime Toyoda (Member) was born in 1991. He received the B.Eng.

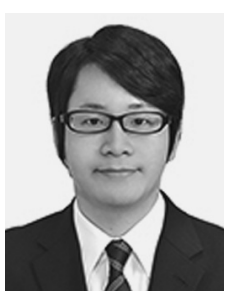
degrees in electrical engineering from Ritsumeikan University, Siga, Japan, in 2013. In April 2013, He entered the master's program of Osaka University Electrical and Electronic Information Engineering. His research is the DC power connector using LLC resonant circuit.

Toshifumi Ise (Fellow) was born in 1957. He received the B.Eng., M.Eng. and Doctor of Engineering degrees in electrical engineering from Osaka University, Osaka, Japan, in 1980, 1982 and 1986 respectively. Since 1990, he has been with the Faculty of Engineering, Osaka University, Osaka, Japan. Currently, he is a professor of Division of Electrical, Electronic and Information Engineering at Graduate School of Engineering, Osaka University. From 1986 to 1990, he was with Nara National College of Technology, Nara, Japan. His research interests are in the areas of power electronics and applied superconductivity for power systems including superconducting magnetic energy storage (SMES) and future power systems including many distributed generations. 